Genome Report

\title{
Whole-genome sequence of bioactive streptomycete derived from mangrove forest in Malaysia, Streptomyces sp. MUSC 14
}

\author{
Hooi-Leng Ser ${ }^{1}$, Loh Teng Hern Tan ${ }^{1,2}$, Wen-Si Tan ${ }^{3,4}$, Wai-Fong Yin ${ }^{4}$, Kok-Gan Chan ${ }^{4,5^{*}}$
}

\author{
Article History \\ ${ }^{1}$ Novel Bacteria and Drug Discovery (NBDD) Research Group, Microbiome \\ and Bioresource Research Strength, Jeffrey Cheah School of Medicine and \\ Received: 8 February 2021; \\ Health Sciences, Monash University Malaysia, 47500 Bandar Sunway, \\ Selangor Darul Ehsan, Malaysia; ser.hooileng@monash.edu (H-LS) \\ Received in Revised Form: \\ ${ }^{2}$ Clinical School Johor Bahru, Jeffrey Cheah School of Medicine and Health \\ 10 April 2021; \\ Sciences, Monash University Malaysia, Johor Bahru 80100, \\ Accepted: 12 April 2021; \\ Malaysia; loh.teng.hern@ monash.edu (LT-HT) \\ Available Online: 22 April \\ 2021 \\ ${ }^{3}$ Illumina Singapore Pte Ltd, Woodlands Industrial Park E1, Singapore; \\ tmarilyn36@gmail.com (W-ST) \\ ${ }^{4}$ Division of Genetics and Molecular Biology, Institute of Biological Sci- \\ ences, Faculty of Science, University of Malaya, 50603 Kuala Lumpur, \\ Malaysia; yinwaifong@yahoo.com (W-FY) \\ ${ }^{5}$ Vice Chancellor Office, Jiangsu University, Zhenjiang 212013, PR China \\ *Corresponding author: Kok-Gan Chan, kokgan@um.edu.my (K-GC)
}

\begin{abstract}
The contribution of streptomycetes to human health is undeniably important and significant, given that these filamentous microbes can produce interesting compounds that can be used to cure deadly infections and even cancer. Isolated from the east coast of Peninsular Malaysia, Streptomyces sp. MUSC 14 has shown significant antioxidant capacity. The current study explores the genomic potential of MUSC 14 via a genome mining approach. The genome size of MUSC 14 is $10,274,825$ bp with $\mathrm{G}+\mathrm{C}$ content of $71.3 \%$. AntiSMASH analysis revealed a total of nine biosynthetic gene clusters (with more than 80 $\%$ similarities to known gene clusters). This information serves as an important foundation for subsequent studies, particularly the purification and isolation of bioactive compounds by genetic manipulation techniques.
\end{abstract}

Keywords: Streptomyces, antioxidant, mangrove, genome, MUSC 14, actinobacteria

\section{Short Introduction}

Gifted with the ability to form spores, streptomycetes are ubiquitous in nature and produce a diverse array of secondary metabolites that can be exploited for the benefit of humanity ${ }^{[1-16]}$. One of the significant breakthroughs in streptomycetes research is the discovery of streptomycin (from the soil bacterium, Streptomyces griseus) by Professor 
Waksman and his team - which subsequently led him to the Nobel Award in Medicine later in $1960^{[13,17-21]}$. As a matter of fact, the continuous search for pharmaceutically important compounds led to another (one half jointly) Nobel Prize in Physiology or Medicine in 2015 awarded to Professor William C. Campbell and Professor Satoshi Ōmura for the discovery of avermectin, which was isolated from a soil streptomycete, Streptomyces avermitilis ${ }^{[22-27]}$. The search for bioactive compounds from this prolific genus seems like a never-ending journey, with researchers now hunt for them in unique environments such as hot springs, volcanic soils, deserts, deep-sea, and the mangrove forest ${ }^{[28-42]}$. The hypothesis behind searching these special habitats is that microbes may come up with adaptation strategies to ensure their survival in the harsh condition like drastic temperature changes, salinity, and oxygen availability, which in turn may lead to the production of interesting compounds and drive the emergence of a novel bacterium ${ }^{[43-50]}$. Streptomyces sp. MUSC 14 was isolated from the mangrove forest on the west coast of Peninsular Malaysia during a screening program for bioactive actinobacteria ${ }^{[4,51,52]}$. A thorough investigation conducted on the strain has reflected the antioxidant potential of MUSC 14, attributed to its production of bioactive secondary metabolites, including pyrrolopyrazines and fatty acid esters ${ }^{[51,53-55]}$. The current study aims to obtain the genome sequence of Streptomyces sp. MUSC 14 before exploring the genomic potential of this strain.

\section{Data description}

The whole genomic DNA extraction of MUSC 14 was carried out using Masterpure ${ }^{\mathrm{TM}}$ DNA purification kit (Epicentre, Illumina Inc., Madison, WI, USA), preceding RNase treatment (Qiagen, USA) ${ }^{[56-58]}$. Subsequently, the DNA library was constructed with Nextera $^{\mathrm{TM}}$ DNA Sample Preparation kit (Nextera, USA). The library quality was evaluated by Bioanalyzer 2100 high sensitivity DNA kit (Agilent Technologies, Palo Alto, CA) ${ }^{[59,60]}$. Paired-end sequencing was performed on the Illumina MiSeq platform with MiSeq Reagent Kit $2(2 \times 250 \text { bp; Illumina Inc., Madison, WI, USA })^{\left[16,61,{ }^{62]}\right.}$. Post-trimming step, de novo assembly of the paired-end reads on CLC Genomics Workbench version 7 (CLC bio, Denmark) resulted in 174 contigs and an $\mathrm{N}_{50}$ contig size of $162,032 \mathrm{bp}$. The genome size of MUSC 14 is 10,274,825 bp, with an average coverage of 211.0 -fold and $\mathrm{G}+\mathrm{C}$ content of $71.3 \%$ (Table 1). The genome sequence of MUSC 14 has been deposited at DDBJ/EMBL/GenBank under accession of MLYN00000000. The version described in this paper is the first version.

Following genome assembly, MUSC 14 genome was annotated on Rapid Annotation using Subsystem Technology (RAST) and NCBI Prokaryotic Genome Annotation Pipeline $(\mathrm{PGAP})^{[63-66]}$. Gene prediction was performed using Prodigal (version 2.6) ${ }^{[67]}$, while ribosomal RNA (rRNA) and transfer RNA (tRNA) were predicted using RNAmmer ${ }^{[68]}$ and tRNAscan SE version 1.21 ${ }^{[69]}$, respectively. The whole genome of MUSC 14 consists of 8,799 protein-coding genes and 81 RNA genes (tRNA: 74, rRNA:4).

Table 1. General genomic features of Streptomyces sp. MUSC 14.

\begin{tabular}{cc}
\hline Properties & Streptomyces sp. MUSC 14 \\
\hline Genome size (bp) & $10,274,825$ \\
Contigs & 174 \\
Contigs N50 (bp) & 162,032 \\
G + C content $\%$ & 71.3 \\
\hline
\end{tabular}




$\begin{array}{cc}\text { Genome coverage } & 211.0 \\ \text { Protein coding genes } & 8,799 \\ \text { tRNA } & 74 \\ \text { rRNA }(5 S, 16 S, 23 S) & 4(2,1,1)\end{array}$
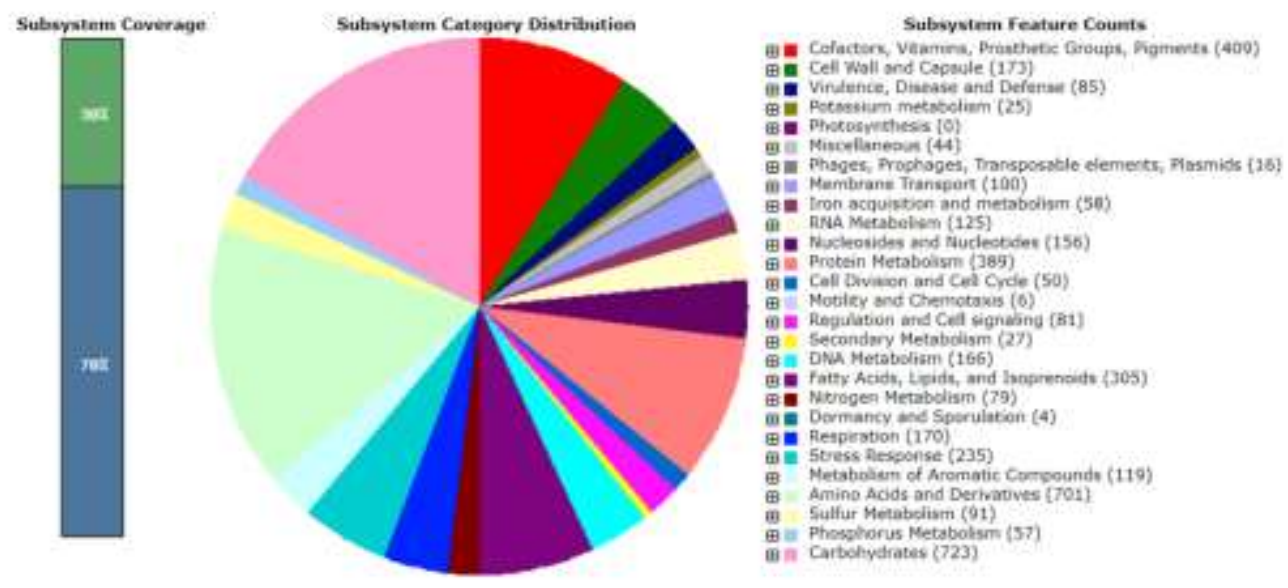

Figure 1. Annotation of MUSC $14^{\mathrm{T}}$ genome using Rapid Annotation using Subsystem Technology (RAST).

The annotation on RAST showed that most of the protein-coding genes were involved in metabolic processes, with the highest number of genes involved in carbohydrates metabolism (7.60\%) (Figure 1). Subsequent analysis to investigate the genomic potential of MUSC 14 on antibiotics \& Secondary Metabolite Analysis SHell (antiSMASH) ${ }^{[70-74]}$ revealed a total of nine biosynthetic gene clusters displaying more than $80 \%$ similarities to known biosynthetic gene clusters. Besides detecting the gene cluster responsible for the production of the earthy odorant geosmin (100\% gene similarities), there is one biosynthetic gene cluster related to nonribosomal peptides production and reflects $100 \%$ gene similarities with thioholgamide $\mathrm{A} /$ thioholgamide $\mathrm{B}$ biosynthesis. Thioholgamide $\mathrm{A}$ and $\mathrm{B}$ were initially isolated from a mangrove-derived streptomycete, Streptomyces malaysiense MUSC $136^{\mathrm{T}}$, and possess cytotoxic activities against cancer cell lines ${ }^{[75,76]}$. Recently, a research group in Germany has published an article studying the mechanisms involved behind the cytotoxic and anti-proliferative activities of thioholgamide $\mathrm{A}^{[75,77]}$. The team showed that thioholgamide A induces apoptosis via caspase 3 and PARP cleavage (at concentrations comparable to staurosporine) ${ }^{[77]}$. Furthermore, it appears that thioholgamide A inhibits oxidative phosphorylation in tumor cells without displaying much toxicity towards nontumorigenic cells and zebrafish embryos, thus making the compound an appealing candidate that to be developed as anti-cancer therapeutics. Harnessing the genomic potential of microbes, including Streptomyces sp. is indeed one way forward in drug discovery ${ }^{[78-80]}$. Combined with the conventional methods, including optimization of fermentation media and improvement in extraction processes, the activation of biosynthetic gene clusters via heterologous expression or introduction of promoters in the native host can potentially yield bioactive compound(s) of interest in high purity and quantity, allowing its large-scale production for pharmaceutical use ${ }^{[81-85]}$. 
Author Contributions: HLS, LTHT, and WST carried out the experiments and analyzed the data. WFY and KGC provided vital guidance, technical support, and proofreading for the work. All authors approved the final draft.

Funding: This work was supported by the University of Malaya for High Impact Research Grant (UM-MOHE HIR Nature Microbiome Grant No. H-50001-A000027 and No. A000001-5001) and PPP Grant (PG090-2015B) awarded to K-GC.

Conflicts of Interest: The authors declare no conflict of interest.

\section{References}

1. Law JW-F, Letchumanan V, Tan LT-H, et al., The rising of "modern actinobacteria” era. Prog Microbes Mol Biol 2020; 3(1).

2. Chang T-L, Huang T-W, Wang Y-X, et al., An actinobacterial Isolate, Streptomyces sp. YX44, produces broadspectrum antibiotics that strongly inhibit Staphylococcus aureus. Microorganisms 2021; 9(3): 630.

3. Law JW-F, Pusparajah P, Ab Mutalib N-S, et al., A review on mangrove actinobacterial diversity: the roles of Streptomyces and novel species discovery. Prog Microbes Mol Biol 2019; 2(1).

4. Lee L-H, Zainal N, Azman A-S, et al., Diversity and antimicrobial activities of actinobacteria isolated from tropical mangrove sediments in Malaysia. Sci World J 2014; 2014.

5. Rizo-Liendo A, Sifaoui I, Cartuche L, et al., Evaluation of indolocarbazoles from Streptomyces sanyensis as a novel source of therapeutic agents against the brain-eating amoeba Naegleria fowleri. Microorganisms 2020; 8(5): 789.

6. Kemung HM, Tan LT-H, Khan TM, et al., Streptomyces as a prominent resource of future anti-MRSA drugs. Front Microbiol 2018; 9: 2221.

7. Ser H-L, Chan K-G, Tan W-S, et al., Complete genome of mangrove-derived anti-MRSA streptomycete, Streptomyces pluripotens MUSC 135 . Prog Microbes Mol Biol 2018; 1(1).

8. Terra L, Dyson P, Ratcliffe N, et al., Biotechnological potential of Streptomyces siderophores as new antibiotics. Curr Med Chem 2020.

9. Tan LT-H, Lee L-H, and Goh B-H, Critical review of fermentation and extraction of anti-Vibrio compounds from Streptomyces. Prog Microbes Mol Biol 2020; 3(1).

10. Lee SR, Song JH, Song J-H, et al., Chemical identification of isoflavonoids from a termite-associated Streptomyces sp. RB1 and their neuroprotective effects in murine hippocampal HT22 cell line. Int J Mol Sci 2018; 19(9): 2640.

11. Lee L-H, Goh B-H, and Chan K-G, Actinobacteria: Prolific producers of bioactive metabolites. Front Microbiol $2020 ; 11$.

12. Tan LTH, Mahendra CK, Yow YY, et al., Streptomyces sp. MUM273b: A mangrove- derived potential source for antioxidant and UVB radiation protectants. MicrobiologyOpen 2019; 8(10): e859.

13. Quinn GA, Banat AM, Abdelhameed AM, et al., Streptomyces from traditional medicine: sources of new innovations in antibiotic discovery. J Med Microbiol 2020; 69(8): 1040.

14. Law JW-F, Law LN-S, Letchumanan V, et al., Anticancer drug discovery from microbial sources: The unique mangrove streptomycetes. Molecules 2020; 25(22): 5365.

15. Ser H-L, Tan LT-H, Law JW-F, et al., Focused review: cytotoxic and antioxidant potentials of mangrove-derived Streptomyces. Front Microbiol 2017; 8: 2065.

16. Ser H-L, Tan W-S, Ab Mutalib N-S, et al., Genome sequence of Streptomyces mangrovisoli MUSC $149^{\mathrm{T}}$ isolated from intertidal sediments. Braz J Microbiol 2018; 49(1): 13-15. 
17. Schatz A, Bugle E, and Waksman SA, Streptomycin, a substance exhibiting antibiotic activity against GramPositive and Gram-Negative Bacteria. Proc Soc Exp Biol Med 1944; 55(1): 66-69.

18. Waksman SA, Streptomycin: background, isolation, properties, and utilization. Science 1953; 118(3062): 259266.

19. Waksman SA, Reilly HC, and Harris DA, Streptomyces griseus (Krainsky) Waksman and Henrici. J Bacteriol 1948; 56(3): 259.

20. Waksman SA, Reilly HC, and Johnstone DB, Isolation of streptomycin-producing strains of Streptomyces griseus. J Bacteriol 1946; 52(3): 393.

21. Waksman SA, Schatz A, and Reilly HC, Metabolism and the chemical nature of Streptomyces griseus. J Bacteriol 1946; 51(6): 753.

22. Ikeda H, Kotaki H, and Omura S, Genetic studies of avermectin biosynthesis in Streptomyces avermitilis. J Bacteriol 1987; 169(12): 5615-5621.

23. Burg RW, Miller BM, Baker EE, et al., Avermectins, new family of potent anthelmintic agents: producing organism and fermentation. Antimicrob Agents Chemother 1979; 15(3): 361-7.

24. Van Voorhis WC, van Huijsduijnen RH, and Wells TN, Profile of William C. Campbell, Satoshi Ōmura, and Youyou Tu, 2015 Nobel Laureates in Physiology or Medicine. Proc Natl Acad Sci 2015; 112(52): 15773-15776.

25. Ikeda H, Ishikawa J, Hanamoto A, et al., Complete genome sequence and comparative analysis of the industrial microorganism Streptomyces avermitilis. Nat Biotechnol 2003; 21(5): 526-531.

26. Kim SB and Goodfellow M, Streptomyces avermitilis sp. nov., nom. rev., a taxonomic home for the avermectinproducing streptomycetes. Int J Syst Evol Microbiol 2002; 52(6): 2011-2014.

27. Egerton J, Ostlind D, Blair L, et al., Avermectins, new family of potent anthelmintic agents: efficacy of the B1a component. Antimicrob Agents Chemother 1979; 15(3): 372-378.

28. Sivalingam P, Hong K, Pote J, et al., Extreme environment Streptomyces: potential sources for new antibacterial and anticancer drug leads? Int J Microbiol 2019; 2019.

29. Sivakala KK, Gutiérrez-García K, Arul Jose P, et al., Desert environments facilitate unique evolution of biosynthetic potential in Streptomyces. Molecules 2021; 26(3): 588.

30. Wang P, Wang D, Zhang R, et al., Novel macrolactams from a deep-sea-derived Streptomyces species. Mar Drugs 2021; 19(1): 13.

31. Braña AF, Fiedler H-P, Nava H, et al., Two Streptomyces species producing antibiotic, antitumor, and antiinflammatory compounds are widespread among intertidal macroalgae and deep-sea coral reef invertebrates from the central Cantabrian Sea. Microb Ecol 2015; 69(3): 512-524.

32. Amin A, Ahmed I, Khalid N, et al., Streptomyces caldifontis sp. nov., isolated from a hot water spring of Tatta Pani, Kotli, Pakistan. Antonie Van Leeuwenhoek 2017; 110(1): 77-86.

33. Naragani K, Mangamuri U, Muvva V, et al., Antimicrobial potential of Streptomyces cheonanensis VUK-a from mangrove origin. Int. J. Pharm. Pharm. Sci 2016; 8: 53-57.

34. Karim MRU, In Y, Zhou T, et al., Nyuzenamides A and B: Bicyclic peptides with antifungal and cytotoxic activity from a marine-derived Streptomyces sp. Organic Letters 2021.

35. Kim MC, Cullum R, Hebishy A, et al., Mersaquinone, a new tetracene derivative from the marine-derived Streptomyces sp. EG1 exhibiting activity against methicillin-resistant Staphylococcus aureus (MRSA). Antibiotics 2020; 9(5): 252.

36. Masand M, Sivakala KK, Menghani E, et al., Biosynthetic potential of bioactive streptomycetes isolated from arid region of the Thar desert, Rajasthan (India). Front Microbiol 2018; 9: 687. 
37. Hamed M, Abdrabo M, and Fahmy N, Distribution and characterization of actinomycetes in mangrove habitats (Red Sea, Egypt) with special emphasis on Streptomyces mutabilis M3MT483919. J Pure Appl Microbiol 2021; $15(1)$.

38. Risdian C, Landwehr W, Rohde M, et al., Streptomyces bathyalis sp. nov., an actinobacterium isolated from the sponge in a deep sea. Antonie Van Leeuwenhoek 2021; 114(4): 425-435.

39. Zhu Q, Cheng W, Song Y, et al., Complete genome sequence of the deep South China Sea-derived Streptomyces niveus SCSIO 3406, the producer of cytotoxic and antibacterial marfuraquinocins. PLoS One 2021; 16(3): $\mathrm{e} 0248404$.

40. Goel N, Fatima SW, Kumar S, et al., Antimicrobial resistance in biofilms: Exploring marine actinobacteria as a potential source of antibiotics and biofilm inhibitors. Biotechnology Reports 2021: e00613.

41. Jia F, Liu C, Zhao J, et al., Streptomyces vulcanius sp. nov., a novel actinomycete isolated from volcanic sediment. Antonie Van Leeuwenhoek 2015; 107(1): 15-21.

42. Bae M, Kim H, Park S, et al., Discovery of new bioactive secondary metabolites produced by Streptomyces strains derived from volcanic islands. Planta Med 2016; 82(S 01): P676.

43. Parrilli E, Tedesco P, Fondi M, et al., The art of adapting to extreme environments: the model system Pseudoalteromonas. Physics of Life Reviews 2019.

44. Tan LT-H, Chan K-G, Khan TM, et al., Streptomyces sp. MUM212 as a source of antioxidants with radical scavenging and metal chelating properties. Front Pharmacol 2017; 8: 276.

45. Pettit RK, Culturability and secondary metabolite diversity of extreme microbes: expanding contribution of deep sea and deep-sea vent microbes to natural product discovery. Marine Biotechnology 2011; 13(1): 1-11.

46. Lee L-H, Zainal N, Azman A-S, et al., Mumia flava gen. nov., sp. nov., an actinobacterium of the family Nocardioidaceae. Int J Syst Evol Microbiol 2014; 64(5): 1461-1467.

47. Law JW-F, Ser H-L, Duangjai A, et al., Streptomyces colonosanans sp. nov., a novel actinobacterium isolated from Malaysia mangrove soil exhibiting antioxidative activity and cytotoxic potential against human colon cancer cell lines. Front Microbiol 2017; 8: 877.

48. Ser H-L, Yin W-F, Chan K-G, et al., Antioxidant and cytotoxic potentials of Streptomyces gilvigriseus MUSC $26^{\mathrm{T}}$ isolated from mangrove soil in Malaysia. Prog Microbes Mol Biol 2018; 1(1).

49. DasSarma S, Extreme microbes: salt-loving microorganisms are helping biologists understand the unifying features of life and molecular secrets of survival under extreme conditions. Am Sci 2007; 95(3): 224-232.

50. Sayed AM, Hassan MH, Alhadrami HA, et al., Extreme environments: microbiology leading to specialized metabolites. J Appl Microbiol 2020; 128(3): 630-657.

51. Kemung HM, Tan LT-H, Chan K-G, et al., Antioxidant activities of Streptomyces sp. strain MUSC 14 from mangrove forest soil in Malaysia. BioMed Res Int 2020; 2020: 6402607.

52. Kemung HM, Tan LT-H, Chan K-G, et al., Streptomyces sp. strain MUSC 5 from mangrove forest in Malaysia: Identification, antioxidant potential and chemical profiling of its methanolic extract. Prog Microbes Mol Biol $2020 ; 3(1)$

53. Kumar S, Kumar N, Roy P, et al., Synthesis, anti-inflammatory, and antiproliferative activity evaluation of isoindole, pyrrolopyrazine, benzimidazoisoindole, and benzimidazopyrrolopyrazine derivatives. Mol Divers 2013; 17(4): 753-766.

54. Kim J, Park M, Choi J, et al., Design, synthesis, and biological evaluation of novel pyrrolo [1, 2-a] pyrazine derivatives. Bioorg Med Chem Lett 2019; 29(11): 1350-1356. 
55. Seo Y, Lee JH, Park S-h, et al., Expansion of chemical space based on a pyrrolo [1, 2-a] pyrazine core: Synthesis and its anticancer activity in prostate cancer and breast cancer cells. Eur J Med Chem 2020; 188: 111988.

56. Ser H-L, Tan W-S, Yin W-F, et al., Whole-genome sequence of a novel, mangrove-derived streptomycete, Streptomyces malaysiense strain MUSC 136 ${ }^{\mathrm{T}}$. Prog Drug Discov Biomed Sci 2020; 3(1).

57. Ser H-L, Ab Mutalib N-S, Yin W-F, et al., Genome sequence of Streptomyces antioxidans MUSC $164^{\mathrm{T}}$ isolated from mangrove forest. Prog Microbes Mol Biol 2018; 1(1).

58. Ser H-L, Tan W-S, Mutalib N-SA, et al., Genome sequence of Streptomyces gilvigriseus MUSC $26^{\mathrm{T}}$ isolated from mangrove forest. Braz J Microbiol 2018; 49(2): 207-209.

59. Ser H-L, Tan W-S, Cheng H-J, et al., Draft genome of starch-degrading actinobacterium, Microbacterium mangrovi MUSC $115^{\mathrm{T}}$ isolated from intertidal sediments. Prog Drug Discov Biomed Sci 2018; 1(1).

60. Ser H-L, Yin W-F, Chan K-G, et al., Genome sequence of Novosphingobium malaysiense strain MUSC 273 ${ }^{\mathrm{T}}$, novel alpha-proteobacterium isolated from intertidal soil. Prog Microbes Mol Biol 2018; 1(1).

61. Letchumanan V, Ser H-L, Chan K-G, et al., Genome sequence of Vibrio parahaemolyticus VP103 strain isolated from shrimp in Malaysia. Front Microbiol 2016; 7: 1496

62. Chan K-G and Tan W-S, Insights into Cedecea neteri strain M006 through complete genome sequence, a rare bacterium from aquatic environment. Standards in Genomic Sciences 2017; 12(1): 1-7.

63. Aziz RK, Bartels D, Best AA, et al., The RAST Server: rapid annotations using subsystems technology. BMC Genomics 2008; 9(1): 1-15.

64. Overbeek R, Olson R, Pusch GD, et al., The SEED and the Rapid Annotation of microbial genomes using Subsystems Technology (RAST). Nucleic Acids Res 2014; 42(D1): D206-D214.

65. Brettin T, Davis JJ, Disz T, et al., RASTtk: a modular and extensible implementation of the RAST algorithm for building custom annotation pipelines and annotating batches of genomes. Sci Rep 2015; 5(1): 1-6.

66. Tatusova T, DiCuccio M, Badretdin A, et al., NCBI prokaryotic genome annotation pipeline. Nucleic Acids Res 2016; 44(14): 6614-6624.

67. Hyatt D, Chen G-L, LoCascio PF, et al., Prodigal: prokaryotic gene recognition and translation initiation site identification. BMC Bioinformatics 2010; 11(1): 1-11.

68. Lagesen K, Hallin P, Rødland EA, et al., RNAmmer: consistent and rapid annotation of ribosomal RNA genes. Nucleic Acids Res 2007; 35(9): 3100-3108.

69. Lowe TM and Eddy SR, tRNAscan-SE: a program for improved detection of transfer RNA genes in genomic sequence. Nucleic Acids Res 1997; 25(5): 955-964.

70. Blin K, Shaw S, Steinke K, et al., antiSMASH 5.0: updates to the secondary metabolite genome mining pipeline. Nucleic Acids Res 2019; 47(W1): W81-W87.

71. Weber T, Blin K, Duddela S, et al., antiSMASH 3.0-a comprehensive resource for the genome mining of biosynthetic gene clusters. Nucleic Acids Res 2015; 43(W1): W237-W243.

72. Blin K, Wolf T, Chevrette MG, et al., antiSMASH 4.0-improvements in chemistry prediction and gene cluster boundary identification. Nucleic Acids Res 2017; 45(W1): W36-W41.

73. Medema MH, Blin K, Cimermancic P, et al., antiSMASH: rapid identification, annotation and analysis of secondary metabolite biosynthesis gene clusters in bacterial and fungal genome sequences. Nucleic Acids Res 2011; 39(suppl_2): W339-W346.

74. Blin K, Medema MH, Kazempour D, et al., antiSMASH 2.0 - a versatile platform for genome mining of secondary metabolite producers. Nucleic Acids Res 2013; 41(W1): W204-W212. 
75. Kjaerulff L, Sikandar A, Zaburannyi N, et al., Thioholgamides: Thioamide-containing cytotoxic RiPP natural products. ACS Chem Biol 2017; 12(11): 2837-2841.

76. Ser H-L, Palanisamy UD, Yin W-F, et al., Streptomyces malaysiense sp. nov.: a novel Malaysian mangrove soil actinobacterium with antioxidative activity and cytotoxic potential against human cancer cell lines. Sci Rep 2016; 6(1): 1-12.

77. Dahlem C, Siow WX, Lopatniuk M, et al., Thioholgamide A, a new anti-proliferative anti-tumor agent, modulates macrophage polarization and metabolism. Cancers (Basel) 2020; 12(5): 1288.

78. Ab Mutalib N-S, Wong SH, Ser H-L, et al., Bioprospecting of microbes for valuable compounds to mankind. Prog Microbes Mol Biol 2020; 3(1).

79. Zotchev SB, Sekurova ON, and Katz L, Genome-based bioprospecting of microbes for new therapeutics. Curr Opin Biotechnol 2012; 23(6): 941-947.

80. Cabello LO, Microorganisms as Alternative Sources of New Natural Products, in Natural products-From bioactive molecules to human health. 2020, IntechOpen.

81. Liu Z, Zhao Y, Huang C, et al., Recent advances in silent gene cluster activation in Streptomyces. Frontiers in Bioengineering and Biotechnology 2021; 9.

82. Csolleiova D, Knirschova R, Rezuchova B, et al., An efficient system for stable markerless integration of large biosynthetic gene clusters into Streptomyces chromosomes. Appl Microbiol Biotechnol 2021; 105(5): 2123-2137.

83. Kang H-S and Kim E-S, Recent advances in heterologous expression of natural product biosynthetic gene clusters in Streptomyces hosts. Curr Opin Biotechnol 2021; 69: 118-127.

84. Liu S, Wang M, Du G, et al., Improving the active expression of transglutaminase in Streptomyces lividans by promoter engineering and codon optimization. BMC Biotechnol 2016; 16(1): 1-9.

85. Komatsu M, Uchiyama T, Ōmura S, et al., Genome-minimized Streptomyces host for the heterologous expression of secondary metabolism. Proc Natl Acad Sci 2010; 107(6): 2646-2651.

Author(s) shall retain the copyright of their work and grant the Journal/Publisher right for the first publication with the work simultaneously licensed under:

Creative Commons Attribution-NonCommercial 4.0 International (CC BY-NC 4.0). This license allows for the copying, distribution and transmission of the work, provided the correct attribution of the original creator is stated. Adaptation and remixing are also permitted. 